\title{
Trend Analysis of ISARC
}

\author{
Takatoshi UENO \\ Institute of Technology, Shimizu Corporation \\ 4-17, Etchujima 3-Chome, Koto-ku, Tokyo 135, Japan
}

\begin{abstract}
International Symposium on Automation and Robotics in Construction was firstly held in Pittsburgh in 1984. From this year, the symposium has been held yearly in various countries in the world. More than one thousand papers were presented at fourteen symposiums. These papers are valuable data for researches and engineers in this field.

The purpose of this paper is to analyze the trend of ISARC papers. We divided fourteen ISARCs into four period and analyzed chronological trend.

\section{Introduction}

Trend analysis of ISARC (International Symposium on Automation and Robotics in Construction) was executed by the working group in CCRR (Council for Construction Robot Research) in Japan. This project was proposed by Mr. Miyatake who is former president of IAARC (International Association for Automation and Robotics in Construction). The result of the trend analysis was partially reported by Mr. Miyatake at keynote speech of the 14th ISARC.

The paper will describe the result of the analysis which is based on the database of the ISARC from 1 st to 14 th.

\section{History of ISARC}

In 1984, Professor D. A. Sangrey of Carnegie Mellon University organized Workshop Conference called "Robotics in Construction". This conference is the original of ISARC. The first and second symposium were held in Pittsburgh as Workshop Conference. The third symposium was held in Marseilles, France as an international symposium titled "International Joint Conference on CAD and Robotics in Architecture and Construction". Fourth was held in Haifa, Israel titled "International Symposium on Robotics and Artificial Intelligence in Building Construction". Fifth symposium was held in Japan as "International Symposium in Robotics in Construction" where the current style of ISARC was established. The name "ISARC" was firstly used in 6th symposium held in San Francisco. 14th ISARC was held in Pittsburgh again in 1997.
\end{abstract}

\section{Database of ISARC Papers}

We made database of papers presented at the past fourteen ISARCs. About one thousand and thirty papers were published in ISARC from 1 st to 14 th. We modified the database structure of CARD (Construction Automation Research Database) which Professor C. Haas, University of Texas at Austin, created. CARD database covers 4th through 10th ISARC, and the rest was newly added. 
Table 1: Classification of papers

\begin{tabular}{|c|c|}
\hline $\begin{array}{l}\text { A. Views for Automation and Robotics in } \\
\text { Construction } \\
\text { 1. Needs and Feasibility of Robotics in } \\
\text { Construction } \\
\text { 2. Social Issues in Exploitation } \\
\text { 3. Design for Automation and Robotics } \\
\text { 4. State of the Art of Automation and Robotics } \\
\text { in Construction } \\
\text { 5. Health and Safety Issues } \\
\text { 6. Construction Automation Concept } \\
\text { 7. Economic and Management Issues } \\
\text { 8. Other }\end{array}$ & $\begin{array}{l}\text { C. Elemental Technologies for Automation and } \\
\text { Robotics } \\
\text { 1. Mobile Robots and Navigation Systems } \\
\text { 2. Manipulator } \\
\text { 3. Control Systems for Construction Robots and } \\
\text { Systems } \\
\text { 4. Sensor and End-Effector } \\
\text { 5. Programming and Software } \\
\text { 6. Man-Machine Interface and Virtual Reality } \\
\text { 7. Image Processing and Robot Vision } \\
\text { 8. Others }\end{array}$ \\
\hline $\begin{array}{l}\text { B. Design, Construction Planning and } \\
\text { Management } \\
\text { 1. Construction Planning, Management System } \\
\text { 2. Computer Graphics, CAD/CAM, Modeling, } \\
\text { Simulation } \\
\text { 3. AI, Expert System, Neural Network } \\
\text { 4. Exploitation of Information Technology } \\
\text { 5. Other }\end{array}$ & $\begin{array}{l}\text { D. Application } \\
\text { 1. Earthwork and Foundation } \\
\text { 2. Concrete Placing and Finishing } \\
\text { 3. Assembly and Finishing Operations } \\
\text { 4. Masonry Construction } \\
\text { 5. Material Handling } \\
\text { 6. Tunneling and Underground Construction } \\
\text { 7. Road Construction } \\
\text { 8. Hazardous Environment, Dismantling } \\
\text { 9. Inspection, Repair and Maintenance } \\
\text { 10. Surveying and Positioning } \\
\text { 11. Building Construction Automation } \\
\text { 12. Piping } \\
\text { 13. Underwater Construction } \\
\text { 14. Others }\end{array}$ \\
\hline
\end{tabular}

We used "Excel" work sheet for the database. Fields of the database are shown from 1) to 11).

1) "ID": Identification number for each paper

2) "SOURCE": Source of the paper

3) "AUTHOR 1", "AUTHOR 2": First author and second author

4) "PAG": Page in the proceeding

5) "TEC 1", "TEC 2": Classification of the paper. ISARC papers are classified by items shown in table 1.

6) "STG": Development stage of the paper (C: Concept, P: Prototype, E: Commercial)

7) "COUNTRY": Nationality of the first author

8) "REG": Region of the country of the first author (A: Japan, B: North America, C: Europe, D: Others)

9) "INST": Organization of the first author

10) "TYP": Type of organization (A: Academic Institution, P: Private Company, G: Government, O: Others)

11) "TITLE": Title of the Paper 


\section{Trend analysis of ISARC}

We analyzed the trend of ISARC from various point of view. To analyze chronological trend of ISARC, we divided 14 ISARCs into four groups as follows;

ISARC 1 st to 2 nd (cradle period)

ISARC 3rd to 6th (growing period)

ISARC 7th to 10th (developing period I)

ISARC 11 th to 14 th (developing period II)

First and second ISARC (those are not called ISARC) are special workshop. Third to fourteenth ISARC are divided every four years, because ISARC is held in USA, Europe, Europe(or other country), Japan. Chronological trends are analyzed using these groups.

\subsection{Number of papers in each ISARC}

Number of papers in ISARC increased from 1 st to 5 th symposium. After the 5 th symposium, it has reached to a plateau fluctuating around 80 papers. Number of papers in 5 th, 9th and 13th, those are held in Japan, are large compared to other ISARC. The average number of papers in ISARC from third to fourteenth is 83.5. Chronological trend of number of papers is shown in figure 2. It was increased in first three period, but slightly decreased in recent period (11 th to 14 th).

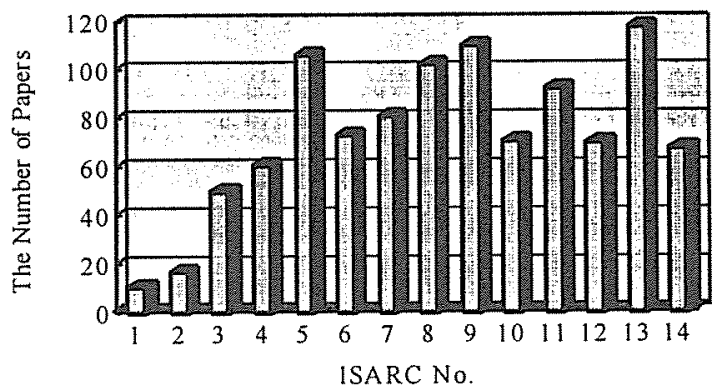

Fig. 1: Number of papers in ISARC

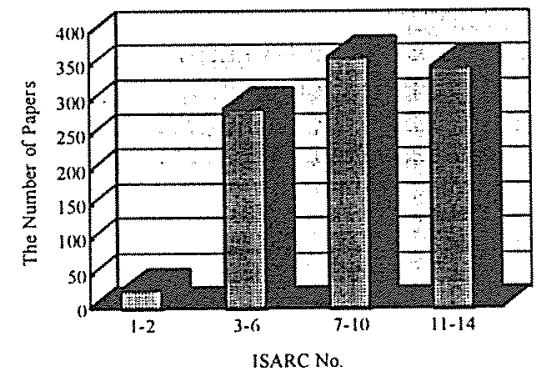

Fig. 2: Chronological trend of number of papers in ISARC

\subsection{Trend of number of papers in regions}

Figure 3 shows the number of papers in each regions. About one third of them are occupied by Europe and same as Japan. Chronological trend of number of papers in each regions is shown in figure 4. Number of papers in North America is decreased, and number of papers in others is increased. While number of papers in Europe and Japan are stable.

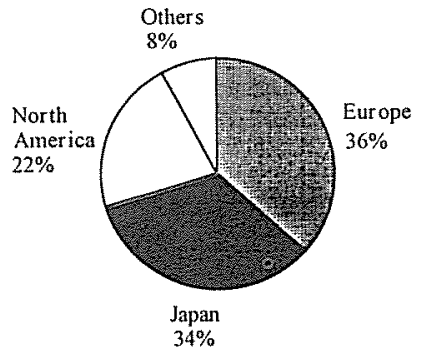

Fig. 3: Number of Papers in each region

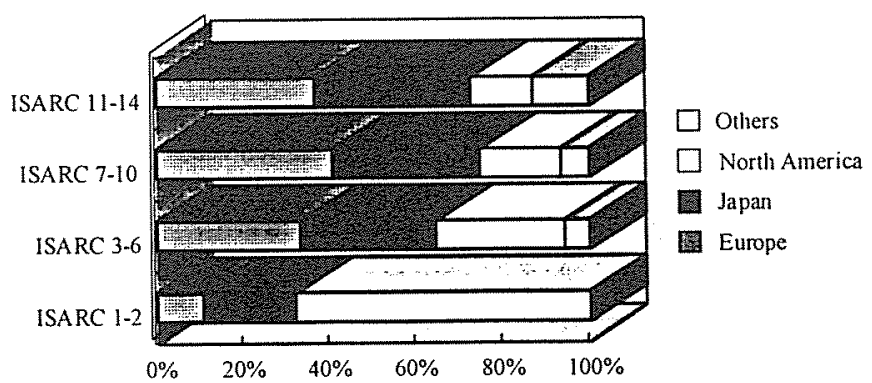

Fig. 4: Chronological trend of number of papers in each region 


\subsection{Trend of number of papers in each countries}

Figure 5 shows the number of papers in each countries. Figure 6 shows Chronological trend of numbers of papers in major countries. Japan is the most active country in this field, and number of papers has been increased in each period. Second largest number of papers were reported from USA, but those number are decreeing recently. In Europe, papers from UK keeps good amount. On the other hand, numbers of papers from France decreased recently.

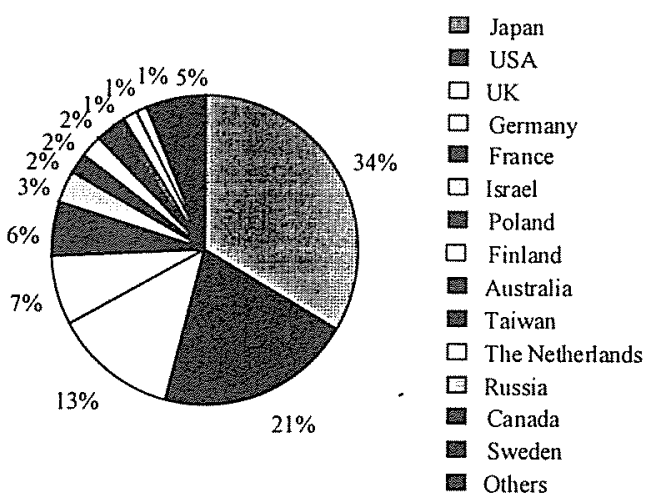

Fig. 5: Number of papers in each countries

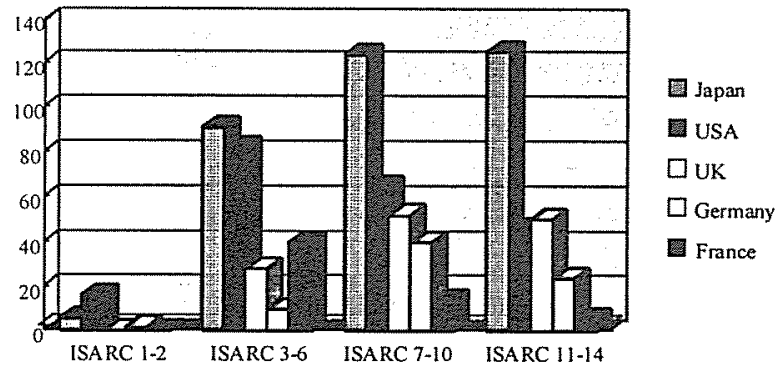

Fig. 6: Chronological trend of number of papers in major countries

\subsection{Chronological trend of technical area of ISARC papers}

Figure 7 shows distribution of technical area of ISARC papers. Figure 8 shows Chronological trend of number of papers in each technical area. All papers were divided into four technical areas as follows,
A. Views for Automation and Robotics in Construction
B. Design, Construction Planning and Management
C. Elemental Technologies for Automation and Robotics
D. Application

$37 \%$ of papers are classified to "Application". Rest papers are classified to "Views", "Design, Construction Planning and Management" and "Elemental Technologies" equally (21\%). Regarding chronological trend, "Application" and "Elemental Technologies" were increasing, on contrary "Views" and "Design, Construction Planning and Management" were decreeing.

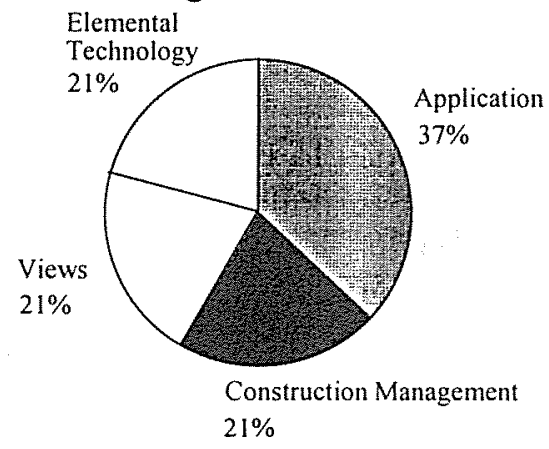

Fig.7: Number of papers in each technical area

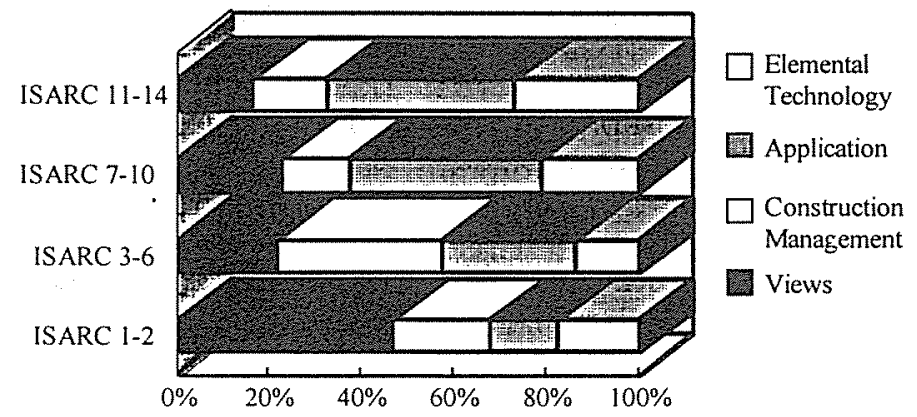

Fig. 8: Chronological trend of number of papers in each technical area 


\subsection{Chronological trend of research theme}

\section{(1) Views for Automation and Robotics in Construction}

Category A is "Views for Automation and Robotics in Construction". Figure 9 shows the distribution of theme in category $A$. Chronological trend of major two theme of category A are shown in Figure 10. The most popular theme in category A is "Needs and feasibility study (A1)", and second popular theme is "State of the Art (A4)". The database includes keynote speech and panel discussion, so that the percentage of "State of the Art" may appeared large.

From chronological trend of those two theme, either of them are decreasing. This fact indicates that interest of researcher changed from general discussion to specific or concrete theme of R\&D of Automation and Robotics in construction.
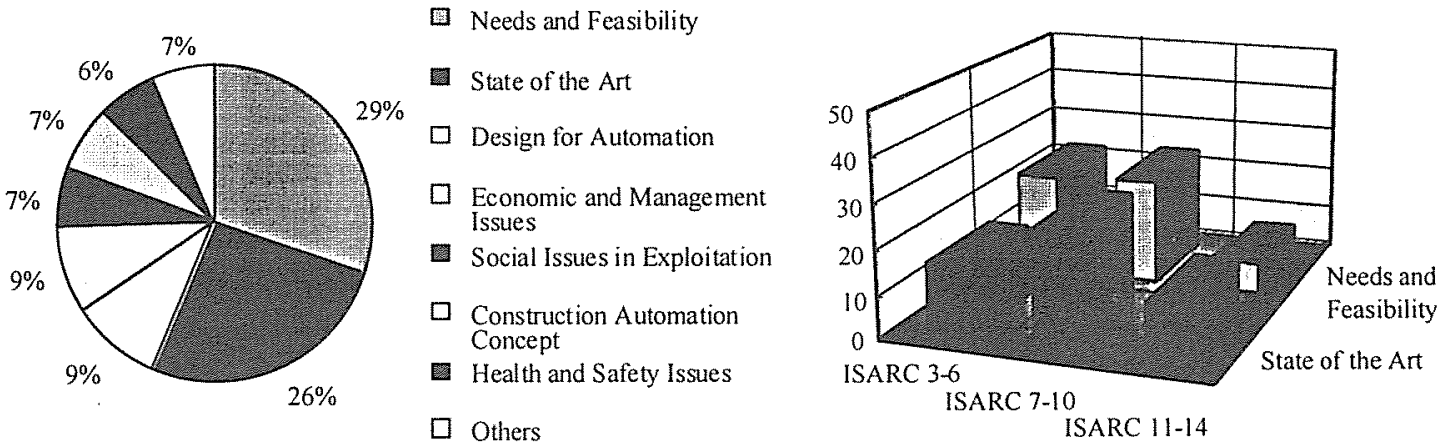

Fig. 9:Distribution of theme in category A Fig. 10: Chronological trend of major theme in category $\mathrm{A}$

\section{(2) Design, Construction Planning and Management}

Category B is "Design, Construction Planning and Management". Figure 11 shows the distribution of theme in category B. Chronological trend of major three theme of category B are shown in Figure 12. The most popular theme in category B is "AI, Expert System (B3)", and second popular theme is "CG, CAD, Modeling and Simulation (B2)". The third one is "Construction Management (B1)".

From chronological trend of those three theme, "AI, Expert System", which used to be active, has been decreased. "CG, CAD, Modeling and Simulation" has been slightly decreased.

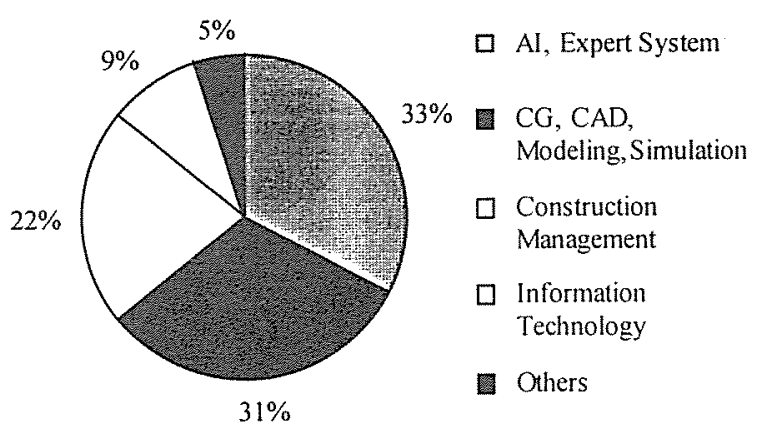

Fig. 11: Distribution of theme in category B

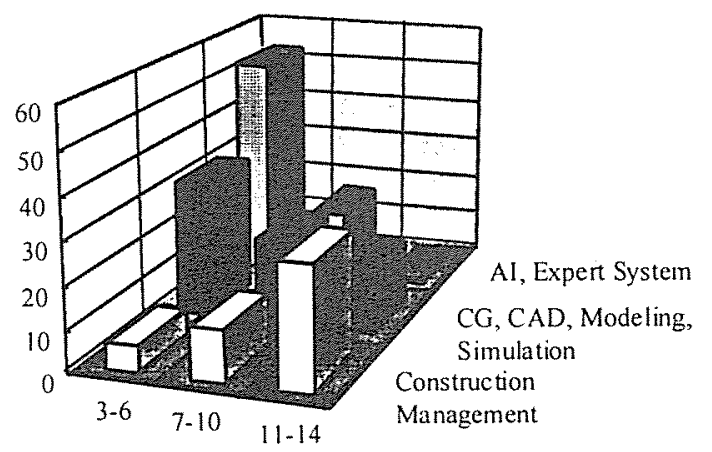

Fig. 12: Chronological trend of major theme in category $\mathrm{B}$ 
On the other hand, "Construction Management" has been increasing recently. Especially, it is increased in fourth period (from 11th to 14th). So, we analyzed B1 theme "Construction Management (Planning, Scheduling, Site Layout)" in this period.

1) Specific research theme

"Planning" is the most popular theme. (10 papers in 29) "Planning" is mostly construction process planning. "Scheduling" and "Site Layout" are also popular. (6 papers, 4 papers) Those papers are mostly presented by academic institutions.

2) Author's country

Seven papers are reported from Japan, six papers are from USA and five are from Taiwan.

\section{(3) Elemental Technologies for Automation and Robotics}

Category C is "Elemental Technologies for Automation and Robotics". Figure 13 shows the distribution of theme in category $\mathrm{C}$. Chronological trend of major two theme of category $\mathrm{C}$ are shown in Figure 14. The most popular theme in category $\mathrm{C}$ is "Control Systems (C3)", and second popular theme is "Mobile Robot and Navigation (C1)".

From chronological trend of those two theme, "Control Systems" has been increasing. On contrary, "Mobile Robot and Navigation" has been decreased. We analyzed C3 theme "Control Systems" in this period (11th to 14th).

1) Specific research theme

Control system for excavator or construction machine is the most popular theme in this field. (10 papers in 32) Research about wall climbing robot and Large manipulator for construction application are also popular. Those papers are mostly presented by universities.

2) Author's country

Ten papers are reported from Poland, seven are from Japan, five are from UK and three are from Germany.

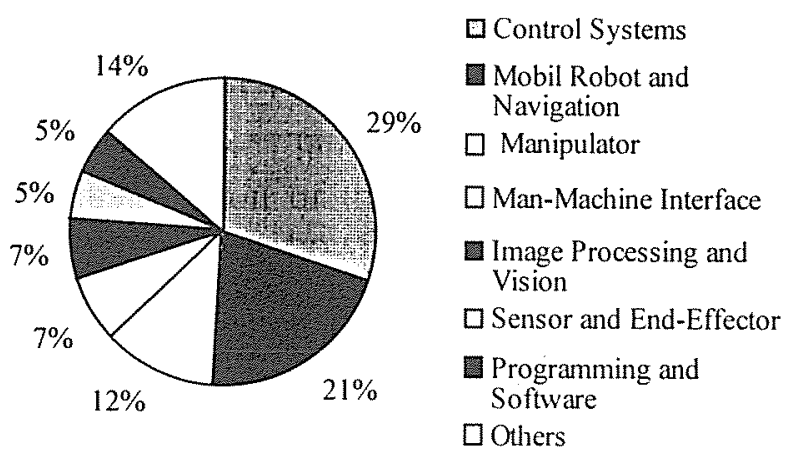

Fig. 13: Distribution of theme in category $\mathrm{C}$

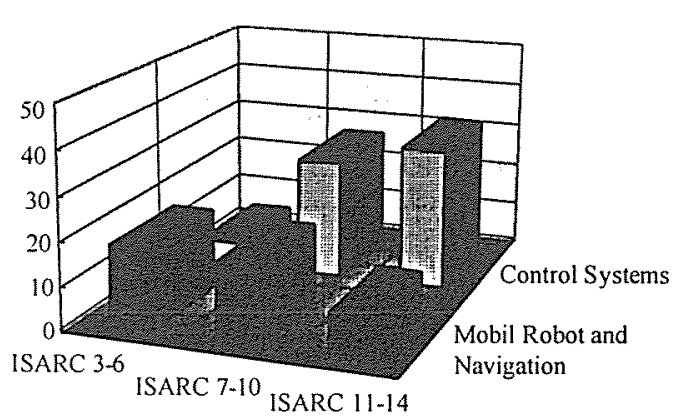

Fig. 14: Chronological trend of major theme in category $\mathrm{C}$

\section{(4) Application}

Category D is "Application". Figure 15 shows the distribution of theme in category D. Chronological trend of major two theme of category D are shown in Figure 16. The most popular theme in category D is "Tunneling and Underground (D6)", and second popular theme is "Assembly and Finishing Operation (D3)". 
From chronological trend of those two theme, there is not significant trend.

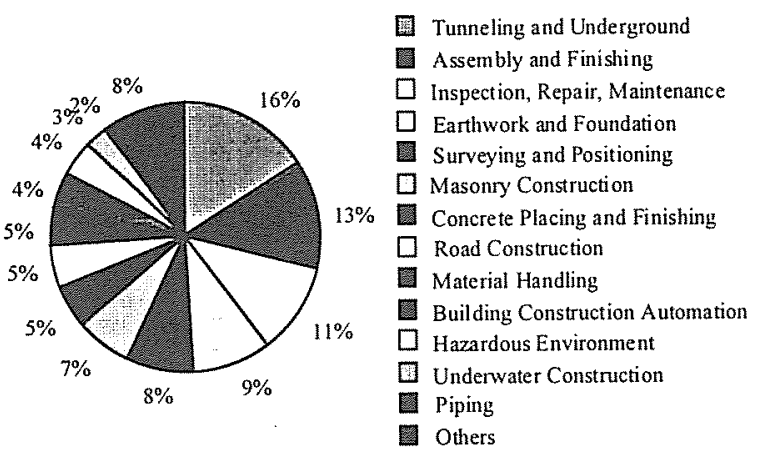

Fig. 15: Distribution of theme in category D

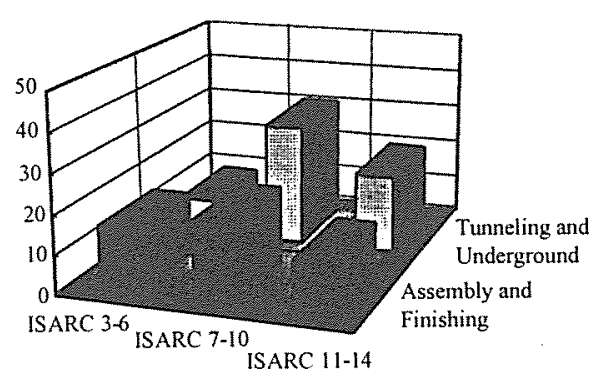

Fig. 16: Chronological trend of major theme in category $\mathrm{D}$

\subsection{Chronological trend of development stage}

ISARC papers are categorized following three stages.
C: Concept stage
P: Prototype stage
E: Commercial stage

Figure 17 shows distribution of development stage of ISARC papers. Figure 18 shows Chronological trend of number of papers in each development stage. Concept stage is more than half $(56 \%)$. Commercial stage is only $3 \%$.

Regarding chronological trend, "Prototype" is increasing, on contrary "Concept" is decreeing.

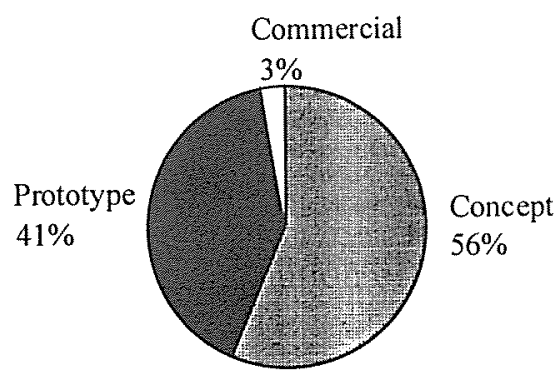

Fig. 17: Distribution of development stage

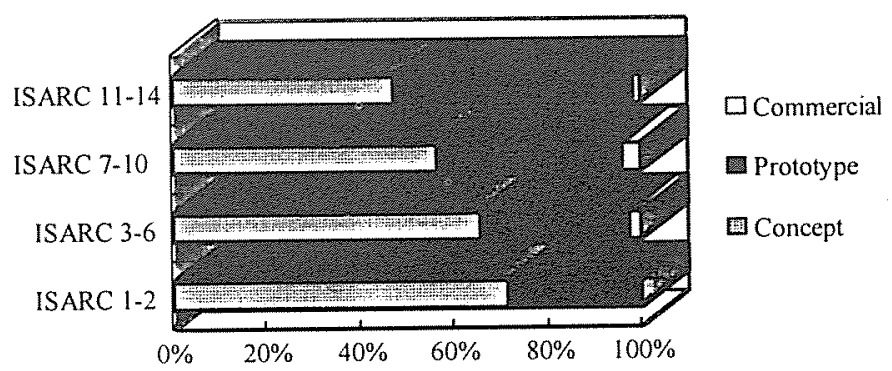

Fig. 18: Chronological trend of development stage

\section{Conclusion}

At the first ISARC held in Pittsburgh, all presentation were made by only three nations, USA, Japan, Finland. But, at the 13th ISARC held in Tokyo in 1996, there were 118 papers, 350 participants, and 20 participating countries. ISARC has developed in these years. (Fig. 19) The number of presentation from Asian countries such as Taiwan whose economy has been rapidly developing, has been increasing recently.

ISARC is the only one international symposium which treats automation and robotics in construction. I hope that research and development of this field will be more active and ISARC will keep its activity in the future. 


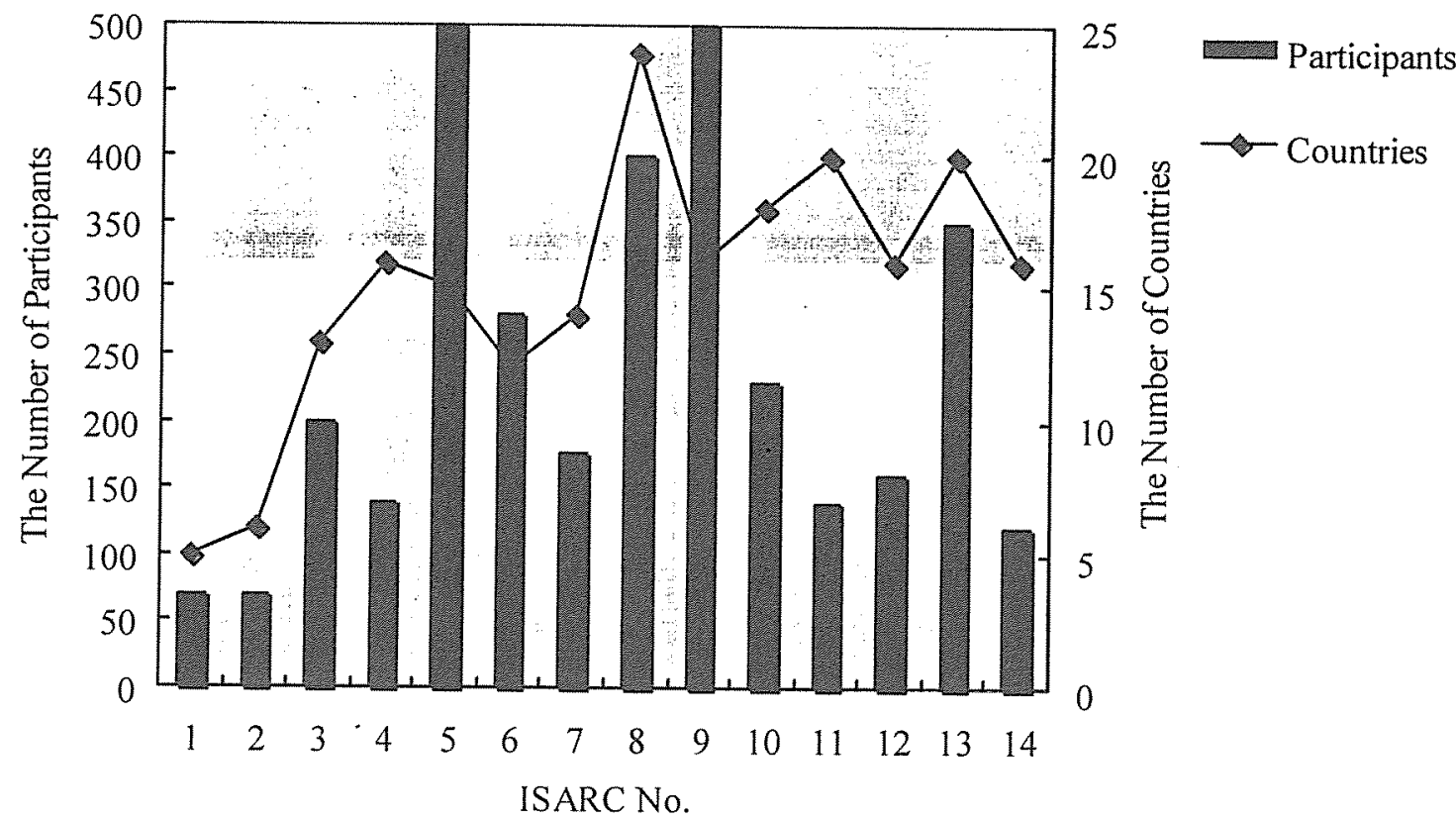

Fig. 19: Number of participants and participating countries in ISARC

\section{Acknowledgment}

As descried before, this trend analysis of ISARC was executed by the working group in CCRR in Japan. Professor Hasegawa was the chairman of this working group. This project was proposed by former IAARC president Mr. Miyatake. Professor Haas of UT Austin kindly provided his CARD database. Professor Ohbayashi who is the chairman of CCRR, professor Kano of Waseda University, Dr. Arai of Kajima Corporation, Mr. Yoshida of Shimizu Corporation and Mr. Hata of JARA, they gave me proper advice and information. The author would like to thank all of those people who assisted this project.

\section{References}

1. Proceedings of the 1 st to the 14th International Symposium on Automation and Robotics in Construction, 1984-1997.

2. Ochoa-Franco, L., Haas, C., Dailey, C. and Traver, A., "Construction Automation Research Database (CARD) ", Proceedings of the 11th International Symposium on Automation and Robotics in Construction, Brighton, UK, May, 1994. 